\title{
Pobreza, "questão social" e seu enfrentamento
}

\author{
Poverty, "social issue" and its confrontation
}

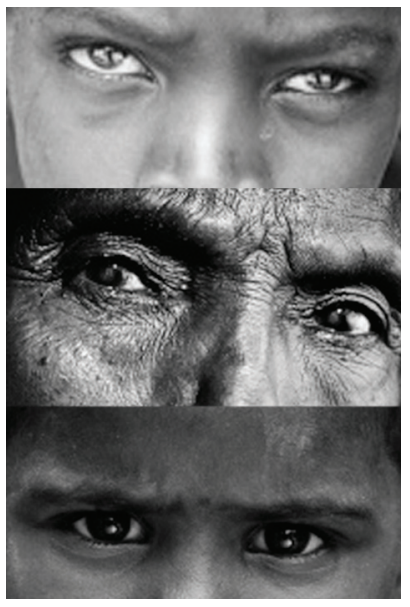

Carlos Montaño*

Resumo: Visamos aqui problematizar as diferentes concepções de pobreza e "questão social" na tradição liberal, e suas formas típicas de enfrentamento, no contexto do liberalismo clássico, no século XIX, do keynesianismo, no século XX, e do neoliberalismo, a partir da atual crise do capital. Com isto, oferecemos uma reflexão sobre aspectos para uma caracterização histórico-crítica de pobreza e "questão social". Finalmente, procuramos problematizar os caminhos para a busca de diminuição da desigualdade social, mediante políticas compensatórias no contexto atual.

Palavras-chave: Pobreza. Questão social. Desigualdade.

\begin{abstract}
We aim at questioning the various concepts of poverty and "social issue" in the liberal tradition, and their typical ways of confrontation, in the context of the classical liberalism in the nineteenth century, of the keynesianism, in the twentieth century and of the neo-liberalism from the current crisis of the capital. Doing so, we offer a reflection concerning aspects related to a historical and critical characterization of poverty and "social issue". Finally, we question the ways of reducing social inequality, through compensatory policy in the current context.
\end{abstract}

Keywords: Poverty. Social issue. Inequality.

* Doutor em Serviço Social e professor associado da Universidade Federal do Rio de Janeiro (UFRJ), Brasil. Autor dos livros: Microempresa na era da globalização (Cortez, 1999); Terceiro setor e questão social (Cortez, 2002); A natureza do Serviço Social (Cortez, 2007) e Estado, classe e movimento social (Cortez, 2010, em coautoria). É coordenador da Biblioteca Latino-Americana de Serviço Social (Cortez). Foi membro da Direção Executiva da Alaeits (2006-09) e atualmente é coordenador nacional de relações internacionais da Abepss (gestões 2009-10 e 2011-12). Realizou pós-doutoramento (pela Capes) no Instituto Superior Miguel Torga (Coimbra, Portugal) entre 2009 e 2010.E-mail: c_montano_br@yahoo.com.br. 


\section{Concepções sobre pobreza, "questão social" e seu enfrentamento}

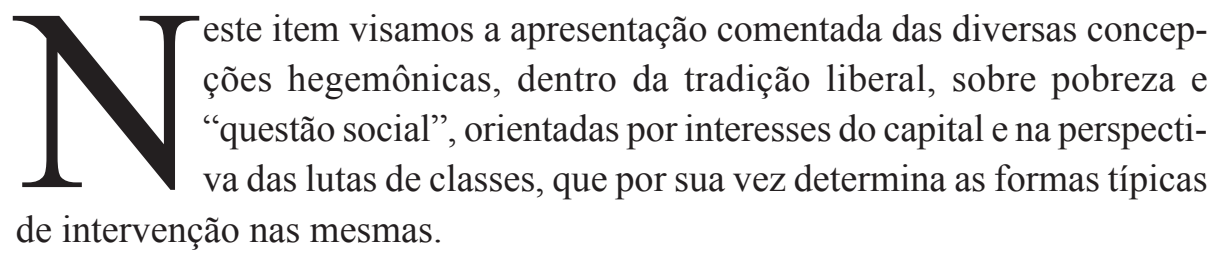

\section{As concepções hegemônicas de pobreza e "questão social" no capitalismo concorrencial}

A expressão "questão social" começa a ser empregada maciçamente a partir da separação positivista, no pensamento conservador, entre o econômico e o social, dissociando as questões tipicamente econômicas das "questões sociais" (cf. Netto, 2001, p. 42). Assim, o "social" pode ser visto como "fato social", como algo natural, a-histórico, desarticulado dos fundamentos econômicos e políticos da sociedade, portanto, dos interesses e conflitos sociais. Assim, se o problema social (a "questão social") não tem fundamento estrutural, sua solução também não passaria pela transformação do sistema.

A origem desta separação são os acontecimentos de 1830-48. No momento em que a classe burguesa perde seu caráter crítico-revolucionário perante as lutas proletárias (cf. Lukács, 1992, p. 109 e ss.), surge um tipo de racionalidade que, procurando a mistificação da realidade, cria uma imagem fetichizada e pulverizada desta. É o que Lukács chama de "decadência ideológica da burguesia". ${ }^{.}$Segundo ele (1992, p. 123), "após o surgimento da economia marxista, seria impossível ignorar a luta de classes como fato fundamental do desenvolvimento social, sempre que as relações sociais fossem estudadas a partir

1. A luta de classe, diz Marx, significou "o dobre de finados da ciência econômica burguesa. Não interessava mais saber se este ou aquele teorema era verdadeiro ou não; mas importava saber o que, para o capital, era útil ou prejudicial”; "a investigação científica imparcial cedeu seu lugar à consciência deformada e às intenções perversas da apologética" (Marx, 1980, p. 11; também citado por Lukács, 1992, p. 110). Nessa esteira, para Lukács, perante as revoltas proletárias, "agora também fogem os ideólogos da burguesia, preferindo inventar os mais vulgares e insípidos misticismos a encarar de frente a luta de classes entre burguesia e proletariado, a compreender cientificamente as causas e a essência desta luta" (Lukács, 1992, p. 112). 
da economia. Para fugir dessa necessidade, surgiu a sociologia como ciência autônoma [...]". Desta forma, "o nascimento da sociologia como disciplina independente faz com que o tratamento do problema da sociedade deixe de lado a sua base econômica; a suposta independência entre as questões sociais e as questões econômicas constitui o ponto de partida metodológico da sociologia" (Lukács, 1992, p. 132).

Começa-se a se pensar então a "questão social", a miséria, a pobreza, e todas as manifestações delas, não como resultado da exploração econômica, mas como fenômenos autônomos e de responsabilidade individual ou coletiva dos setores por elas atingidos. A “questão social”, portanto, passa a ser concebida como "questões" isoladas, e ainda como fenômenos naturais ou produzidos pelo comportamento dos sujeitos que os padecem.

A partir de tal pensamento, as causas da miséria e da pobreza estariam vinculadas (nessa perspectiva) a pelo menos três tipos de fatores, sempre vinculados ao indivíduo que padece tal situação.

Primeiramente a pobreza no pensamento burguês estaria vinculado a um déficit educativo (falta de conhecimento das leis "naturais" do mercado e de como agir dentro dele). Em segundo lugar, a pobreza é visto como um problema de planejamento (incapacidade de planejamento orçamentário familiar). Por fim, esse flagelo é visto como problemas de ordem moral-comportamental (mal-gasto de recursos, tendência ao ócio, alcoolismo, vadiagem etc.).

Surgem com isso as bases para o desenvolvimento de concepções, como a da "cultura da pobreza", onde a pobreza e as condições de vida do pobre são tidas como produto e responsabilidade do limites culturais de cada indivíduo.

- Com esta concepção de pobreza (típica da Europa nos séculos XVI a XIX), o tratamento e o enfrentamento da mesma desenvolve-se fundamentalmente a partir da organização de ações filantrópicas.

Assim, o tratamento das chamadas "questões sociais" passa a ser segmentado (separado por tipo de problemas, por grupo populacional, por território), filantrópico (orientado segundo os valores da filantropia burguesa), moralizador (procurando alterar os aspectos morais do indivíduo) e comportamental (considerando a pobreza e as manifestações da "questão social" como um problema que se expressa em comportamentos, a solução passa por alterar tais comportamentos) (cf. Netto, 1992, p. 47). A ação é então a educação e a filantropia. Surgem assim os abrigos para "pobres" e as organizações de caridade e filantropia. 
$\mathrm{Na}$ Inglaterra, promulga-se a Lei dos Pobres (Poor Law), em 1601, que "instituía um aparato oficial, centrado nas paróquias, destinado a amparar trabalhadores pobres, sob o auspício da taxa dos pobres" (cf. Duayer e Medeiros, 2003, p. 241; também Martinelli, 1991, p. 33 e 55). Isto é, “durante os dois séculos de vigência dessa legislação, a Inglaterra cuidou do pauperismo através da 'beneficência' pelo caminho burocrático" (Duayer e Medeiros, ibidem).

- Em 1834, justamente no contexto de expressivas lutas de classes trabalhistas, o Parlamento inglês começa a entender a própria Lei dos Pobres como "a fonte principal da situação extrema do pauperismo inglês" (ibidem). A partir do pensamento de Malthus, a beneficência "representaria um estímulo à miséria" (ibidem). Assim, a ação filantrópica estaria reforçando e estimulando os costumes e hábitos dos pobres, isto é, as (supostas) causas da pobreza. O sujeito que recebe assistência, beneficiário, acomodar-se-ia a tal situação, tendendo a reproduzir sua condição, sua pobreza. A assistência seria a verdadeira causa da ociosidade, da acomodação, do conformismo, enfim, da pobreza (cf. Martinelli, 1991, p. 58).

Desta forma, em vez de tratar da pobreza com ações filantrópicas/assistenciais (como sendo um problema de déficit ou carência dos pobres), ela passa a ser reprimida e castigada (como sendo uma questão delitiva ou criminal dos pobres). A beneficência e os abrigos passam a ser substituídos pela repressão e reclusão dos pobres. A ideológica expressão de "marginal" começa a adquirir uma conotação de "criminalidade". O pobre, aqui identificado com "marginal", passa a ser visto como ameaça à ordem.

Aqui produz-se a separação entre "pobre" (objeto de ações assistenciais, por mendicância e vadiagem) $e$ "trabalhador" (objeto de serviços de Saúde e Previdência Social); portanto, diferencia-se o indivíduo "integrado" do "desintegrado" ou "disfuncional". 2

Como podemos observar, mesmo existindo uma forte inflexão sobre a concepção de pobreza e seu enfrentamento, justamente com a anulação da Lei

2. Com a encíclica Rerum Novarum, do papa Leão XIII, em 1891, a Igreja Católica expressa suas concepções de pobreza e de solução, como forma de restaurar o pensamento anterior. Questionando o que chama de "solução socialista", defende a propriedade privada e a desigualdade, como direitos e processos naturais, promovendo a concórdia entre as classes e a caridade dos setores mais abastados para com as "classes inferiores" (cf. <http://www.vatican.va/holy_father/leo_xiii/encyclicals/documents/hf_l-xiii_ enc_15051891_rerum-novarum_po.html $>$ ). 
dos Pobres, a partir de 1834, existem algumas características e problemas dessa concepção de "questão social", pobreza e tratamentos:

a. A "questão social" é separada dos seus fundamentos econômicos (a contradição capital/trabalho, baseada na relação de exploração do trabalho pelo capital, que encontra na indústria moderna seu ápice) e políticos (as lutas de classes). É considerada a "questão social” durkheimianamente como problemas sociais, cujas causas estariam vinculadas a questões culturais, morais e comportamentais dos próprios indivíduos que os padecem.

b. A pobreza é atribuída a causas individuais e psicológicas, jamais a aspectos estruturais do sistema social.

c. O enfrentamento, seja a pobreza considerada como carência ou déficit (onde a resposta são ações filantrópicas e beneficência social). Ou seja, ela entendida como mendicância e vadiagem (onde a resposta é a criminalização da pobreza, enfrentada com repressão/reclusão), sempre remete à consideração de que as causas da "questão social" e da pobreza encontram-se no próprio indivíduo, e a uma intervenção psicologizante, moralizadora e contenedora desses indivíduos. Trata-se das manifestações da "questão social" no espaço de quem os padece, no interior dos limites do indivíduo, e não como questão do sistema social.

2. A concepção hegemônica de pobreza e "questão social" no capitalismo monopolista do "Estado de Bem-Estar"

No contexto da expansão capitalista do segundo pós-guerra, a partir da nova condição do capitalismo monopolista, da expansão produtiva fordista e permeado pela organização e lutas dos trabalhadores, desenvolve-se uma nova "estratégia hegemônica" do capital (produtivo-comercial) (ver Montaño e Duriguetto, 2010, p. 149 e ss.), que incorpora (e enquadra) a classe trabalhadora industrial-urbana.

Surge o que os autores chamam de "capitalismo tardio" clássico (Mandel), de "regime de acumulação fordista/keynesiano" (Harvey), o "breve século XX" (Hobsbawm), a "fase de expansão produtivo-comercial" (Arrighi).

Nessa experiência, o Estado assume tarefas e funções essenciais para a nova fase de acumulação capitalista e inibição-institucionalização dos conflitos 
sociais da classe trabalhadora (represando os anseios de superação da ordem e transformando em pontuais demandas dentro da mesma).

Aqui a "questão social" passa a ser como que internalizada na ordem social. Não mais como um problema meramente oriundo do indivíduo, mas como consequência do ainda insuficiente desenvolvimento social e econômico (ou do subdesenvolvimento). Assim, a "questão social" passa de ser um "caso de polícia" para a esfera da política (de uma "política" reduzida à gestão administrativa dos "problemas sociais" e seu enfrentamento institucional), passa a ser tratada de forma segmenda, mas sistemática, mediante as políticas sociais estatais (cf. Netto, 1992).

Nessa perspectiva, a pobreza e a miséria, expressões da "questão social", são vistas, a partir das formulações keynesianas (cf. Keynes, 1985 bem como Montaño e Duriguetto, 2010, p. 55-60 e 161-179), como um problema de distribuição do mercado, como um descompasso na relação oferta/demanda de bens e serviços.

O problema de distribuição estaria vinculado a um déficit de demanda efetiva (por bens e serviços) no mercado, criado pela sobreoferta de força de trabalho não absorvida pela esfera produtiva. Isto é, com o desenvolvimento das forças produtivas (ou, na interpretação keynesiana, em função do ainda insuficiente desenvolvimento), um contingente da população fica excluído do mercado de trabalho, e ao não poder vender sua força de trabalho, não tem fonte de renda que lhe permita adquirir no mercado bens e serviços. Para enfrentar esse hiato, segundo Keynes, o Estado deve passar a intervir em dois sentidos: (a) responder a algumas necessidades (carências)/demandas dessa população carente; (b) criar as condições para a produção e o consumo, incentivando a uma contenção do desemprego ou uma transferência de renda (seguridade social e políticas sociais). Promove-se o chamado "círculo virtuoso" fordista-keynesiano.

Para isso, o Estado passa a absorver e organizar parte do excedente e a redistribui-lo mediante politicas sociais.

Neste contexto, novas e velhas são as características que marcam a compreensão da "questão social" e suas formas de enfrentamento:

a. Esta abordagem avança ao considerar as manifestações da "questão social" como um produto (transitório) do sistema capitalista (ou como resul- 
tado do seu ainda insuficiente desenvolvimento), e não como meras consequências dos hábitos e comportamentos dos indivíduos que padecem as necessidades sociais.

b. Não obstante isso, tal concepção ainda conserva o tratamento segmentado das manifestações da "questão social", tal como no pensamento liberal clássico.

c. Finalmente, considera-se aqui a "pobreza" como um problema de distribuição. Com isso, desloca-se a gênese da "questão social" da esfera econômica, do espaço da produção, da contradição entre capital e trabalho para a esfera política, no âmbito da distribuição, como uma questão entre cidadãos carentes e o Estado. Assim, o tratamento da "questão social" e o combate à pobreza se determina como um processo de redistribuição. Trata-se de garantir, mediante políticas e serviços sociais, o acesso a bens e serviços por parte da população. Assim, não se questionam os fundamentos da ordem: a exploração de trabalho alheio pelo capital, a partir da separação entre possuidores de força de trabalho e proprietários dos meios e condições para efetivá-lo.

3. A pobreza no contexto e no pensamento neoliberal (ou a pobreza do pensamento neoliberal)

No atual contexto de crise capitalista (ver Mandel, 1980 e Mészáros, 2009), a programática neoliberal (cf. Harvey, 2008) supõe a manutenção de um mínimo acionar estatal na área social (cf. Hayek in Montaño, 2002, p. 81-82): focalizado e precário, com programas de combate à fome e à miséria, financiados em parte por doações da "sociedade civil" e com retiros das classes trabalhadoras (rendas obtidas a partir do arrocho salarial, das reformas previdenciárias, da "flexibilização" das leis trabalhistas etc.).

Neste quadro, o pensamento neoliberal concebe o pauperismo mais uma vez como um problema individual-pessoal e, portanto "devolve" à filantropia (individual ou organizacional) a responsabilidade pela intervenção social: surge o debate do "terceiro setor" (cf. Montaño, 2002), da filantropia empresarial (ou "responsabilidade social"), do voluntariado. A autoajuda, a solidariedade local, o benefício, a filantropia substituem o direito constitucional do cidadão de resposta estatal (tal como no keynesianismo). 
Também pensa-se aqui a pobreza vinculada a um problema na esfera da distribuição, mas contrária à perspectiva keynesiana (que entende como oriundo de um "déficit de demanda efetiva no mercado"). Particularmente a partir da crise do capital, pós-1973, essa corrente concebe a pobreza como vinculada a um déficit de oferta de bens e serviços, como um problema de escassez. $\mathrm{O}$ problema estaria no déficit da oferta no mercado, requerendo assim de um processo de desenvolvimento econômico prévio. Para isso, o Estado deveria canalizar toda sua capacidade de arrecadação (superávit primário) para tal propósito. Em lugar de estimular o consumo (com ações redistributivas), o Estado deve estimular o capital a investir, garantindo e preservando o lucro frente às flutuações do mercado, particularmente em contexto de crise. Enquanto isso, a ação social ficará focalizada e precária no âmbito estatal, e de fundamental responsabilidade da ação voluntária e solidária de indivíduos e organizações da sociedade civil.

Assim, a atual estratégia neoliberal de "enfrentamento" da pobreza é diferente da concepção liberal clássica (até o século XVIII — onde se pensa a causa da miséria como um problema de carência, respondendo a ela com a organização da filantropia), é distinta da perspectiva pós-1835 (século XIX - que, a partir da constituição do proletariado como sujeito e de suas lutas desenvolvidas particularmente entre $1830-48$, pensa o pauperismo como mendicância e como crime, tratando assim dela com repressão e reclusão), é diferente da orientação keynesiana (século XX até a crise de 1973 — que considera a "questão social" como um "mal necessário", produzido pelo desenvolvimento social e econômico (ou como um insuficiente desenvolvimento), internalizando a "questão social" e tratando-a sistematicamente mediante as políticas sociais estatais, como direitos, por meio do fornecimento de bens e serviços).

A estratégia neoliberal orienta-se numa tripla ação. Por um lado, a ação estatal, as políticas sociais do Estado, orientadas para a população mais pobre (cidadão usuário); ações focalizadas, precarizadas, regionalizadas e passíveis de clientelismo. Por outro lado, a ação mercantil, desenvolvida pela empresa capitalista, dirigida à população consumidora, com capacidade de compra (cidadão cliente), tornando os serviços sociais mercadorias lucrativas. Finalmente, a ação do chamado "terceiro setor", ou da chamada sociedade civil (organizada ou não), orientada para a população não atendida nos casos anteriores, desenvolvendo uma intervenção filantrópica (ver Montaño, 2002, p. 186 e ss.). 


\section{Desigualdade social e as políticas compensatórias de combate à pobreza (extrema)}

Pretendemos, neste segundo item, avaliar os fundamentos das estratégias de enfrentamento da pobreza, de combate à fome e à miséria (a exemplo das propostas do Banco Mundial, do FMI, e as políticas desenvolvidas nos governos FHC e Lula), como formas políticas compensatórias que nada alteram as fontes e fundamentos da desigualdade social, fundada na contradição capital-trabalho, na exploração da força de trabalho, na acumulação e centralização de capital, que num contexto de crise se vê acirrada. Para tanto necessitamos de uma caracterização crítica de pobreza no capitalismo.

\section{Pobreza e "questão social": uma análise histórico-crítica}

Uma análise crítica sobre a pobreza e sobre a "questão social" exige a superação das concepções anteriormente descritas e comentadas - diferentes concepções desenvolvidas no interior do pensamento liberal em contextos diferentes. Pretendemos fazer isto apresentando alguns fundamentos para uma caracterização histórico-crítica da pobreza e da "questão social" na sociedade capitalista.

Mas por que pensar a pobreza na sociedade capitalista, se em toda sociedade de classes sempre houve pobreza e desigualdade? Será que este fenômeno, quase sempre presente nas diversas organizações sociais ao longo da história, apresenta alguma característica central no modo de produção capitalista (MPC), diferente de outros sistemas sociais? Será que o capitalismo gera uma pobreza que se funda em bases diferentes de outras sociedades?

Numa sociedade de escassez ou carências (não de abundância), onde a produção é insuficiente para satisfazer as necessidades de toda a população, a distribuição equitativa dos bens existentes faria com que toda a produção fosse consumida sem sobrar um excedente para promover o desenvolvimento das forças produtivas. A sociedade não cresceria produtivamente. Nas sociedades de escassez, portanto, a desigualdade de classes (a desigual distribuição da riqueza socialmente existente) é que permitiria o acúmulo de riqueza por parte de alguns e o empobrecimento por parte de outros, permitindo que o exceden- 
te acumulado nas mãos de uns possa ser investido no crescimento produtivo. A desigualdade, em contexto de escassez, é vista pelos liberais como necessária ao crescimento e ao desenvolvimento das forças produtivas. Contrariamente, em sociedades de abundância, onde a produção é suficiente para abastecer toda a população, como é a sociedade capitalista na era dos monopólios, a desigualdade social é produto do próprio desenvolvimento das forças produtivas, e não o resultado do seu insuficiente desenvolvimento, nem a condição para o mesmo. Aqui a desigualdade é consequência do processo que, mesmo em abundância de mercadorias, articula acumulação e empobrecimento.

Assim, em sociedades pré-capitalistas a pobreza é o resultado (para além da desigualdade na distribuição da riqueza) do insuficiente desenvolvimento da produção de bens de consumo, ou seja, da escassez de produtos (ver Netto, 2001, p. 46). Contrariamente, no modo de produção capitalista a pobreza (pauperização absoluta ou relativa, conforme caracteriza Marx, 1980, I, p. 747 e 717) é o resultado da acumulação privada de capital, mediante a exploração (da mais-valia), na relação entre capital e trabalho, entre donos dos meios de produção e donos de mera força de trabalho, exploradores e explorados, produtores diretos de riqueza e usurpadores do trabalho alheio. No MPC não é o precário desenvolvimento, mas o próprio desenvolvimento que gera desigualdade e pobreza. No capitalismo, quanto mais se desenvolvem as forças produtivas, maior acumulação ampliada de capital e maior pobreza (absoluta ou relativa) (cf. Marx, 1980, I, p. 712 e ss.). Quanto mais riqueza produz o trabalhador, maior é a exploração, mais riqueza é expropriada (do trabalhador) e apropriada (pelo capital). Assim, não é a escassez que gera a pobreza, mas a abundância (concentrada a riqueza em poucas mãos) que gera desigualdade e pauperização absoluta e relativa.

Conforme aponta Marx em O capital, "quanto maior a potência de acumular riqueza, maior a magnitude do exército industrial de reserva. E quanto maior esse exército industrial de reserva em relação ao exército ativo, tanto maior a massa da superpopulação. E quanto maior essa massa (de Lázaros da classe trabalhadora) tanto maior o pauperismo" (Marx, 1980, I, p. 747).

Ou seja, quando maior desenvolvimento, maior acumulação privada de capital. O desenvolvimento no capitalismo não promove maior distribuição de riqueza, mas maior concentração de capital, portanto, maior empobrecimento (absoluto e relativo), isto é, maior desigualdade. 
A partir dessa constatação, uma caracterização histórico-crítica da pobreza e da "questão social" deve considerar os seguintes aspectos:

a) "questão social", como fenômeno próprio do MPC, constitui-se da relação capital-trabalho a partir do processo produtivo, suas contradições de interesses e suas formas de enfrentamento e lutas de classes. Expressa a relação entre as classes (e seu antagonismo de interesses) conformadas a partir do lugar que ocupam e o papel que desempenham os sujeitos no processo produtivo (cf. Montaño e Duriguetto, 2010, p. 82-98);

b) a pobreza no MPC, enquanto expressão da "questão social", é uma manifestação da relação de exploração entre capital e trabalho, tendo sua gênese nas relações de produção capitalista, onde se gestam as classes e seus interesses. Como afirmamos, se o pauperismo e a pobre$z a$, em sociedades pré-capitalistas, é resultado da escassez de produtos, na sociedade comandada pelo capital elas são o resultado da acumulação privada de capital. No MPC, não é o precário desenvolvimento social e econômico que leva à pauperização de amplos setores sociais, mas o próprio desenvolvimento (das forças produtivas) éo responsável pelo empobrecimento (absoluto ou relativo) de segmentos da sociedade. Não é, portanto, um problema de distribuição no mercado, mas tem sua gênese na produção (no lugar que ocupam os sujeitos no processo produtivo);

c) desta forma todo enfrentamento da pobreza direcionado ao fornecimento de bens e serviços é meramente paliativo. Toda proposta de desenvolvimento econômico como forma de combater a pobreza (sem enfrentar a acumulação de riqueza, sem questionar a propriedade privada) não faz outra coisa senão ampliar a pauperização (absoluta e/ou relativa). Toda medida de "combate à pobreza" no capitalismo não faz mais do que reproduzi-la, desde que amplia a acumulação de capital. Quanto mais desenvolvimento das forças produtivas, maior a desigualdade e o pauperismo.

d) no entanto, no contexto da ordem do capital, o fornecimento de bens e serviços constitui, em parte, o resultado de demandas e lutas de classes sociais, caracterizando-se assim um processo contraditório entre a sua funcionalidade com a hegemonia e a acumulação capitalista (produtivo-comercial), e a representação de conquistas e direitos dos trabalhadores e cidadãos; 
e) portanto, não há novidade (a não ser nas formas e dimensões que assume) na "questão social" na atualidade. As análises que tratam de uma suposta "nova questão social", de uma "nova pobreza", dos "novos excluídos sociais", constituem abordagens que se sustentam na desvinculação da "questão social" e de suas manifestações (pobreza, carências, subalternidade cultural etc.) dos seus verdadeiros fundamentos: a exploração do trabalho pelo capital. E estes fundamentos permanecem (e permanecerão enquanto a ordem capitalista estiver de pé) inalterados;

f) só as lutas de classes, e a mudança na correlação de forças sociais, poderão reverter esse processo histórico, confirmando e ampliando conquistas e direitos trabalhistas, políticos e sociais, e superando a ordem do capital.

\section{A crise capitalista: causa da pobreza?}

Na ordem do capital a crise é estrutural e intrínseca; é parte necessária do próprio desenvolvimento capitalista e não uma "doença" transitória.

Conforme Marx (1980, III, p. 416), "os ciclos em que se move a indústria moderna [são:] estabilidade, animação crescente, prosperidade, superprodução, craque, estagnação, estabilidade, etc..."

Para o autor d' $O$ capital,

o curso característico da indústria moderna, um ciclo decenal, com a intercorrência de movimentos oscilatórios menores, constituídos de fases de atividade média, de produção a todo vapor, de crise e de estagnação, baseia-se na formação contínua, na maior ou menor absorção e na reconstituição do exército industrial de reserva... (Idem, I, p. 734)

Só a partir desse momento [em que a indústria mecânica se expande para toda a produção e o mercado mundial se consolida] começam a aparecer aqueles ciclos [...] que desembocam sempre numa crise geral, o fim de um ciclo e o começo de outro. Até agora a duração desses ciclos é de dez ou onze anos [...] [porém, este período] é variável [...] o período dos ciclos se irá encurtando gradualmente. (Nota de rodapé de Engels onde acrescenta anotação de Marx, 1980 , I, p. 735 , nota I) 
Para Marx, na medida em que o uso industrial da máquina tende a dissociar o trabalhador dos seus meios de consumo - particularmente em virtude da expulsão do trabalhador do mercado de trabalho e, portanto, do seu meio de subsistência, o salário - , os trabalhadores expulsos transformam-se de compradores em não compradores. Daí decorre que: a) diminuirá a procura daquelas mercadorias; b) cairão os preços das mesmas; c) aumentará o desemprego; d) parte do capital antes destinada à produção de meios de subsistência passará a se reproduzir de outra forma (particularmente na atividade financeira); e) os trabalhadores empregados nessas áreas da produção ficarão privados de parte de seus salários (ver Marx, 1980, I, p. 504-505).

Assim,

o enorme poder de expansão [...] do sistema fabril e sua dependência do mercado mundial geram necessariamente uma produção em ritmo febril, seguida de abarrotamento dos mercados que, ao se contraírem, ocasionam um estado de paralisação. A vida da indústria se converte numa sequência de períodos de atividade moderada, prosperidade, superprodução, crise e estagnação. (Idem, p. 518)

Surgem assim as cíclicas crises de superprodução e de superacumulação.

Uma crise de superprodução é, segundo Mandel (1982, p. 412), uma interrupção do processo de reprodução ampliada de capital ocasionada por uma queda na taxa de lucro, determinando redução dos investimentos e do nível de emprego. Isto se deve à relação desequilibrada entre a (maior) capacidade de produzir e a (menor) capacidade da população de comprar mercadorias a preços que garantam o lucro esperado. Por seu turno, a crise de superacumulação representa o período em que o excesso de capital é de tal ordem que não pode ser investido completamente, garantindo a taxa de lucro esperada (Mandel, 1982, p. $22,75-76$ e 415$)$.

Esses ciclos, na atualidade, conforme demonstra Mandel (1977), configuram-se seguindo: a) um período de expansão ou "auge e prosperidade" (idem, p. 324 e 330) - em que "todos os capitais fluem para a produção e comércio", aumentando o investimento, a produção e o consumo, além da criação de novas empresas, bem como de mais postos de trabalho - , segue-se de $b$ ) uma fase de "superprodução" (idem, p. 325 e 332) — dado o excessivo crescimento da produção em geral, há maior oferta de mercadorias do que a demanda; uma parte 
das mercadorias produzidas não será vendida ou será comercializada a preços cada vez mais baixos, levando a uma queda da taxa de lucro. Daqui deriva $c$ ) um período de "crise e depressão" (idem, p. 325 e 327), com o desemprego, a redução das vendas e a queda dos preços. Reduz-se o investimento na atividade produtiva e comercial, sendo parte do capital entesourado ou redirecionado para a atividade financeira ou até destinado a outras fronteiras. Aumenta o desemprego, diminuindo os salários, e com isto eleva-se a taxa de mais-valia. Finalmente, d) uma nova fase de "recuperação econômica" (idem, p. 324 e 327-328) — com a redução da capacidade de produção a partir da crise, os excedentes de mercadorias diminuíram ou foram totalmente consumidos, e com isso a demanda por bens de consumo passa a superar a oferta. Sobem então os preços das mercadorias, e com os preços das matérias-primas ainda baixos, aumenta a taxa de lucros. Com isso novamente amplia-se o reinvestimento na atividade produtiva e comercial, aumentando assim também os empregos (cf. Marx, 1980, capítulo XV do Livro III, p. 277 e ss.; também Mandel, 1982, p. 75-76).

Desta forma, a própria lógica do desenvolvimento capitalista manifesta-se ciclicamente em crises de superprodução e superacumulação, permeadas pelas lutas de classes. As crises são cíclicas, fenômeno intrínseco e estrutural ao próprio sistema capitalista. Não sendo, as crises, fases estranhas, doenças, mas períodos do próprio desenvolvimento capitalista, formas em que se manifesta a queda tendencial da taxa média de lucros.

Assim, se nas sociedades pré-capitalistas as crises são produto de um déficit de produção (de bens de consumo), insuficiente para atender toda a população - o resultado da escassez ou de uma subprodução de mercadorias (pouca produção em relação à demanda), contrariamente, nas sociedades capitalistas, o que caracteriza uma crise é a superprodução de valores de uso, isto é, excesso de mercadorias que não podem ser consumidas (garantindo a taxa média de lucro esperado) - em virtude da ampliação da capacidade de produção (produto do desenvolvimento tecnológico e intensificação da produtividade) e da reduzida capacidade de compra do trabalhador (resultado do desemprego, perda salarial etc.). "É porque os produtos são invendáveis que a atividade econômica baixa e não porque fisicamente escasseiem" (Mandel, 1978, p. 77-78 e 1980, p. 229).

Por tais motivos é que podemos afirmar que enfrentar e superar a crise capitalista, com ações que se direcionem para uma nova fase de expansão do capital, não resolve a pobreza. 


\section{A desigualdade no mpc e as políticas sociais}

Pelo item anterior concluímos que: a) primeiramente, no MPC, a pobreza (pauperização absoluta ou relativa) é o par dialético da acumulação capitalista; b) em segundo lugar, a crise é estruturalmente o par dialético da expansão ou desenvolvimento capitalista, alternando ciclicamente entre um e outro.

- No primeiro caso, essa relação dialética pobreza/acumulação perpassa e marca todo o debate atual sobre políticas de assistência social, Suas, Bolsa Família, dividindo as águas entre os que concebem as ações ("afirmativas") de combate à fome e à miséria com independência da acumulação capitalista (a qual bate recordes a cada ano) e da propriedade privada - separando claramente a questão da pobreza do processo de acumulação, buscando alterar a "situação da pobreza" sem impactar a redução da acumulação - e aqueles que questionam as ações sociais que não tenham impacto na acumulação ampliada de capital e na propriedade privada - pensando articuladamente pobreza e acumulação e procurando diminuir a pobreza a partir da redução da acumulação capitalista, impactando na gênese da desigualdade social.

- No segundo caso, a relação dialética criselexpansão capitalista corta o debate (e prática) que enfrenta aqueles que visam "resolver" uma "crise" considerada como algo externo ao capital, melhorando e humanizando o capitalismo — onde desenvolvem-se ações voltadas ao "empoderamento", à "economia solidária", ao "participacionismo 'da' sociedade civil" (transmutado em "terceiro setor"), ao estímulo do "autoemprego", o "emprendedorismo", a "responsabilidade social” etc., sem almejar a superação da ordem —, e os que buscam enfrentar a crise como momento constitutivo e necessário do desenvolvimento capitalista, a partir da contradição capital-trabalho e a exploração da classe trabalhadora pelo capital — aqui a luta tem por horizonte político a superação da ordem.

\section{A modo de conclusão}

A partir das considerações anteriores podemos concluir:

1) Não é no mercado, mas na esfera produtiva que se são geradas as contradições fundantes entre as classes na sociedade capitalista: a partir do lugar 
que ocupam ou do papel que desempenham, os sujeitos no processo de produção, derivado da propriedade privada da terra (capitalistas proprietários de terra), da propriedade privada dos meios de produção e reprodução (capitalista industrial, comercial ou bancário) e da mera propriedade de força de trabalho (trabalhador, empregado ou desempregado) (cf. Montaño e Duriguetto, 2010, p. 82 e ss.).

2) A desigualdade no capitalismo não se resolve apenas com uma socialização parcial da riqueza, mas com a eliminação das classes e da exploração do trabalho pelo capital, ou seja, com a superação da ordem capitalista. O sistema capitalista é um sistema estrutural e irremediavelmente desigual: supõe a "exploração" de uma classe por outra; apropriação pelo capitalista do valor produzido pelo trabalhador; subalternização das massas pelo comando econômico/político/ideocultural do capital; expulsão de massa de trabalhadores excedentes ou obsoletos para as necessidades do desenvolvimento e da acumulação capitalistas.

3) As políticas sociais e direitos sociais, políticos e trabalhistas representam também conquistas dos trabalhadores e setores subalternos, que podem diminuir, mas jamais eliminar as desigualdades. Elas são naturais ao capitalismo, produto das contradições capitalistas, e necessárias para a manutenção do MPC.

4) No entanto, a luta por mecanismos de redistribuição de renda, por controle da exploração, por melhores salários, condições de trabalho e direitos trabalhistas, é, no curto prazo, necessária e urgente para o trabalhador, para o movimento social e sindical, para o partido político e, particularmente, para o assistente social.

5) A despeito do anterior, não observamos, nos governos do PT, um direcionamento, nas suas políticas econômica e social, para alterar ou diminuir, sequer mediante mecanismos de redistribuição de renda, a desigualdade social. Vejamos isso.

Se por um lado houve, nos governos do PT, ampliação da cobertura do Bolsa Família, ${ }^{3}$ por outro esta foi acompanhada de:

3. Em 2004 o governo federal (início da gestão Lula) "beneficiou" 3,6 milhões de famílias (em 5.461 municípios); em 2007, foram mais de 10 milhões de famílias. Disponível em: <www.bolsafamilia.gov.br $>$. Acesso em: dez. 2007. 
a) Descaracterização do Fome Zero (cf. Siqueira, 2007).

b) Confirmação da assistencialização da política social, ${ }^{4}$ contratando profissionais no âmbito municipal, com certa precarização das condições de trabalho.

c) Particularmente, a política social perde seu papel "redistributivo" e volta a uma função "compensatória". Conforme expôs Pierre Salama, ${ }^{5}$ o "coeficiente de Gini", ${ }^{6}$ que mede a distribuição da riqueza e a desigualdade social, aplicado antes e depois da "redistribuição" por via de políticas sociais, mostra o pífio impacto dessa ação no Brasil. Enquanto na França o Gini antes é de 0,42 e depois é de 0,31 (tendo a política social relativo impacto na desigualdade ao alterar 14 pontos percentuais), no Brasil antes é de 0,56 e depois é de 0,52 (alterando apenas 4 centésimos).

d) Confirmação da eliminação da dimensão de "direito de cidadania" da ação social estatal.

e) Desuniversalização, focalização e transitoriedade dos serviços sociais, mantendo a "seletividade por renda".

Recebido em 12/3/2012 - Aprovado em 4/4/2012

\section{Referências bibliográficas}

DUAYER, Mário; MEDEIROS, João Leonardo. Miséria brasileira e macrofilantropia: psicografando Marx. Revista de Economia Contemporânea, Rio de Janeiro, v. 7, n. 2, jul./ dez. 2003.

HARVEY, David. O neoliberalismo: história e implicações. São Paulo: Loyola, 2008.

LUKÁCS, Georg. Sociologia. In: NETTO, José Paulo (Org.). Grandes cientistas sociais, São Paulo: Ática, n. 20, 1992.

4. O "benefício" teve um valor médio de R\$ 61 mensais por família, em 2006.

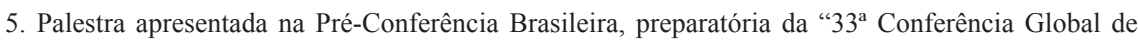
Bem-Estar Social - ICSW", organizada pelos CBCISS. Rio de Janeiro, ESS-UFRJ, 9 de abril de 2008.

6. O coeficiente ou índice de Gini mede a desigualdade, ou igualdade, de renda nos países. A medida vai de 0 a 1 , sendo 0 perfeitatamente igual e 1 completamente desigual. 
MANDEL, Ernest. Tratado de economía marxista. México: Ediciones Era, 1977. t. 1 e 2. . Introdução ao marxismo. Lisboa: Antídoto, 1978.

. La crisis 1974-1980: interpretación marxista de los hechos. México: Serie Popular Era, 1980. . O capitalismo tardio. São Paulo: Abril Cultural, 1982. (Col. Os Economistas.)

MARTINELLI, Maria Lúcia. Serviço social: identidade e alienação. São Paulo: Cortez, 1991.

MARX, Karl. O capital. (Crítica da economia política) Rio de Janeiro: Civilização Brasileira, 1980. Livros I e III, v. 1, 2, 4 e 5.

MÉSZÁROS, István. A crise estrutural do capital. São Paulo: Boitempo, 2009.

MONTAÑO, Carlos. Terceiro setor e questão social: crítica ao padrão emergente de intervenção social. São Paulo: Cortez, 2002.

; DURIGUETTO, Maria Lúcia. Estado, classe e movimento social. São Paulo: Cortez, 2010. (Biblioteca Básica n. 5.)

NETTO, José Paulo. Cinco notas a propósito de la "cuestión social". Temporalis, Brasília, n. 3, 2001.

. Capitalismo monopolista e Serviço Social. São Paulo: Cortez, 1992.

SIQUEIRA, Luana. Programa bolsa-família: política pública de ruptura ou continuidade? Rio de Janeiro: PPG-SS/ESS/UFRJ, 2007. 